\title{
Effect of a combined continuous and intermittent transcutaneous electrical nerve stimulation on pain perception of burn patients evaluated by visual analog scale: a pilot study
}

\author{
This article was published in the following Dove Press journal: \\ Local and Regional Anesthesia \\ 15 December 2015 \\ Number of times this article has been viewed
}

\author{
Irma Pérez-Ruvalcaba' \\ Viridiana Sánchez- \\ Hernández' \\ Arieh R Mercado-Sesma ${ }^{2,3}$ \\ 'Burn Unit, Hospital de Especialidades, \\ Centro Médico Nacional de \\ Occidente, Mexican Institute of \\ Social Security, ${ }^{2}$ Health Sciences \\ Department, Centro Universitario \\ de Tonalá, University of Guadalajara, \\ Guadalajara, Mexico; ${ }^{3}$ Diabetes sin \\ Complicaciones, Zapopan, Mexico
}

Correspondence: Arieh R MercadoSesma

Diabetes sin Complicaciones,

Avenida Nicolás Copérnico 3730,

Colonia Arboledas, Zapopan,

Jalisco, 45070, Mexico

Tel +5233 3631 7250

Email roldan_mercado@hotmail.com
Aim: The aim of this study was to assess the effect of continuous and intermittent electrical transcutaneous nerve stimulation on the perception of pain in patients with burns of different types.

Materials and methods: A pilot study was conducted in 14 patients (age 30.9 \pm 7.5 years) with second- and third-degree burns of different types. The burn types included electrical, fire/ flame, and chemical. All patients received continuous and intermittent electrical transcutaneous nerve stimulation sessions three times per week for 4 weeks. Each session had a duration of 30 minutes. A pair of electrodes were placed around the burn. The primary efficacy endpoint was the perception of pain assessed by a visual analog scale at baseline and at the 30th day.

Results: A significant reduction of pain perception was reported ( $8.0 \pm 1.7$ vs $1.0 \pm 0.5 ; P=0.027$ ) by all patients after electrical stimulation therapy. There were no reports of adverse events during the intervention period.

Conclusion: Electrical stimulation could be a potential nonpharmacological therapeutic option for pain management in burn patients.

Keywords: TENS, burn pain, pain management, electrotherapy

\section{Introduction}

It is estimated that burns cause 195,000 deaths each year. However, the real impact appears in those burns that are not fatal, and cause disability, prolonged hospital stays, psychosocial stigmas, and pain. ${ }^{1}$ The latter is a constant cause of attention because it affects quality of life..$^{2,3}$

Most hospitals try to integrate a multidisciplinary team for the treatment of burn pain. There are two treatment options: pharmacological and nonpharmacological therapy. ${ }^{4}$ Nonpharmacological therapies include psychological techniques to reduce anxiety such as: relaxation, distraction, and cognitive behavioral therapy. ${ }^{4-6}$ This approach seeks to reduce the use of drugs, inpatient hospital stay, and pain as well as improve the quality of life without suffering from the side effects that often occur with the use of pharmacological therapy.

There are other nonpharmacological options for pain relief from diverse etiologies ${ }^{7-10}$ that can complement the treatment following a burn such as transcutaneous electrical nerve stimulation (TENS), which is easy to use, has a low-cost, and no serious adverse effects.

TENS consists of the application of low voltage electric current through electrodes placed on the skin. Its target is nerve or muscle stimulation. Electrical stimulation 
reduces pain through central and peripheral mechanisms..$^{7,11}$ Electrostimulation activates, in a selective form, the afferent fibers $(\mathrm{A} \beta)$ that inhibit the nociceptive information. Moreover, the afferent fibers activate the extra-segmental circuit between the spinal cord and the brain that generates the activation of central inhibitory way of pain. The symmetrical biphasic (faradic)-pulsed currents applied continuously and interruptedly in the same session could generate analgesia and promote healing, respectively.

The objective of this research was to assess the effect of continuous and intermittent electrical stimulation on the pain perception in patients with different types of burns.

\section{Materials and methods}

A pilot study was conducted in 14 adults (18-60 years of age), with similar demographic and socioeconomic characteristics who had second- and/or third-degree burns of different types according to American Burn Association. Both sexes were included.

The inclusion criteria for participation in the study included total body surface area with burns $<50 \%$ and the occurrence of the burn being within 24 hours of the beginning of the study.

All participants had to be able to answer simple questions and understand the nature of the study. All patients were admitted to the Burn Unit of Centro Nacional de Occidente a Specialties Hospital of the Mexican Institute of Social Security. Patients on mechanical ventilation, without intact skin for electrode placement, pregnant women, and those with psychiatric conditions were excluded from the study. All subjects were informed about the use of electrostimulation, and informed consents were signed by each patient. The Local Committee of Scientific Research of the Hospital de Especialidades approved and accepted the protocol.

A visual analog scale was used to assess pain. The scale was graded from 0 "no pain" to 10 "maximum pain" for assessing pain intensity before and after receiving the electrical stimulation therapy. Additionally, a complete physical examination was performed to calculate the total body surface area burned and its depth. The analgesic therapy was the same for all patients according to hospital guidelines.

Electrotherapy was given through a portable device, the Sinapsis 4.0 $0^{\text {TM }}$ (Zerta Technologies, Guadalajara, México) that has output parameters that are different from the other available TENS modalities. It generates automatically a biphasic waveform current with a continuous mode (15 minutes) and an intermittent mode (15 minutes). The current intensity was $40 \mathrm{~mA}$, nonpolar and frequency of 80-100 Hz. The specific waveform current avoids muscular contractions. The device has four channels and delivers the electrical stimulus via eight electrodes placed on the skin. Four self-adhesive electrodes were positioned according to the location of the burn. Rectangular $(5 \times 10 \mathrm{~cm})$ flexible electrodes with a silver and coal conductive layer were used (Pepin Manufacturing, Inc., Lake City, MN, USA). The electrotherapy sessions were performed three times per week (Monday to Friday) for 4 weeks. Each session had a duration of 30 minutes. The procedure was the same for all patients. The position of electrodes over the skin was different in each patient according to the localization of the burn.

The results of clinical characteristics are presented in mean, standard deviation, and ranges. Wilcoxon's rank-sum test was used for analyzing changes in the pain visual ana$\log$ scale. A significant $P$-value of $\leq 0.05$ (two-tailed) was considered statistically significant. All statistical analyses were calculated using SPPS software 17th version (IBM, Corporation, Armonk, New York, USA).

\section{Results}

A total of 14 hospitalized patients (female:male, 1:13) were enrolled in the study and completed all the sessions. The demographic and clinical information of each patient is presented in Table 1. The types of burns included were electrical, fire/flame, and chemical.

After the intervention a statistically significant reduction in pain perception ( $P=0.027 ; 8.0 \pm 1.7$ vs $1.0 \pm 0.5)$ was observed (Table 2). No changes were reported in analgesic use. Only two patients needed a skin graft due to the characteristics of the burn. The nurse team reported a long time analgesic effect on patients after the electrical intervention, but we could not measure this observation effectively.

The length of hospital stay was variable for each patient, being longer for patients who had burns with greater thickness. No adverse effects were reported.

Table I Basal characteristics

\begin{tabular}{ll}
\hline Variable & Results $(\mathbf{N}=14)$ \\
\hline Sex, F/M & $\mathrm{I} / \mathrm{I} 3(7 / 93)$ \\
Age, years & $30.9 \pm 7.5$ \\
Burn degree, second/third & $9 / 5(64 / 36)$ \\
Burn total body surface area, \% & $30.3 \pm 23$ \\
Etiology electric/flame/chemical & $8 / 5 / \mathrm{I}(57 / 36 / 7)$ \\
Hospital stay, days & $51.6 \pm 28.6$ \\
\hline
\end{tabular}

Note: Data presented as mean \pm SD or $n(\%)$.

Abbreviations: $F$, female; $M$, male. 
Table 2 Evaluation of pain after electrical stimulation

\begin{tabular}{llll}
\hline Variable & Basal & Final & $P$-value \\
\hline VAS & $8.0 \pm 1.7$ & $1.0 \pm 0.5$ & $0.027^{*}$ \\
\hline
\end{tabular}

Notes: Data presented as mean \pm SD. *Wilcoxon rank sum test.

Abbreviation: VAS, visual analog scale.

\section{Discussion}

Pain management in burn patients is crucial. Despite conventional treatment, many patients still report pain. Early and efficient management of pain can have a big impact on the quality of the patient's life.

The mechanism by which pain is produced in burn patients may be due to the inflammatory response generated, primary hyperalgesia, or mechanical stimulation of nociceptive receptors at the site of injury, secondary hyperalgesia. ${ }^{12}$

Electrical stimulation can reduce pain through central and peripheral mechanisms. The central mechanism includes activation of the opioid, muscarinic, and serotonin receptors in the spinal cord and brainstem. Peripherally, at site of TENS application, the reduction of pain may be through activation of the opioid and $\alpha-2$ adrenergic receptors involved in analgesia. ${ }^{13}$ This mechanism of action is similar to the pharmacological treatment used for analgesia and sedation in intensive care units, but without the known side effects of these drugs. ${ }^{14}$

TENS reduces pain without the presence of adverse effects. It does not involve any risk for the burn patient because electrodes are placed on the periphery of the injured skin. It also represents a low-cost option. ${ }^{8}$

In addition to the benefit of reducing pain, electrical stimulation can accelerate wound healing by promoting greater cell migration to the site of injury; ${ }^{12}$ by this means, it could reduce number of days of hospital stay and overall costs. ${ }^{15}$

The main limitations of the present study were its design, the lack of a comparison group, and the small sample size. However, despite the different types of burns, a significant decrease in pain was observed in all patients and this protocol opens up the possibility to use other therapies for pain management in burn patients.

\section{Conclusion}

Electrical stimulation could be a potential nonpharmacological therapeutic option for pain management in burn patients.
However, a controlled clinical trial with a bigger sample size and the use of a stratified analysis according to the different etiologies of burns is needed.

\section{Disclosure}

The authors report no conflicts of interest in this work.

\section{References}

1. World Health Organization. Burns. Geneva: World Health Organization; 2012.

2. Edwards RR, Smith MT, Klick B, et al. Symptoms of depression and anxiety as unique predictors of pain-related outcomes following burn injury. Ann Behav Med. 2007;34(3):313-322.

3. Taal LA, Faber AW. Burn injuries, pain and distress: exploring the role of stress symptomatology. Burns. 1997;23(4):288-290.

4. Richardson P, Mustard L. The management of pain in the burns unit. Burns. 2004;35(7):921-936.

5. De JongAE, Middelkoop E, FaberAW,Van Loey NE. Non-pharmacological nursing interventions for procedural pain relief in adults with burns: a systematic review. Burns. 2007;33(7):811-827.

6. European Burns Association. European Practice Guidelines for Burn Care. AK's-Hertogenbosch, the Netherlands: European Burns Association; 2013.

7. Charman RA. Part 3: Bioelectric potentials and tissue currents. Physiotherapy. 1990;76(10):643-653.

8. Watson T. Electrotherapy: Evidence-based Practice. 12th ed. United Kingdom: Churchill-Livingston; 2008: Chapter 16.

9. Gersh MR, Wolf SL. Applications of transcutaneous electrical nerve stimulation in the management of patients with pain: state-of-the-art update. Phys Ther. 1985;65:314-336.

10. Bril V, England J, Franklin GM, et al. Evidence-based guideline: treatment of painful diabetic neuropathy: report of the American Academy of Neurology, the American Association of Neuromuscular and Electrodiagnostic Medicine, and the American Academy of Physical Medicine and Rehabilitation. Neurology. 2011;76:1758-1765.

11. DeSantana JM, Walsh DM, Vance C, Rakel BA, Sluka KA. Effectiveness of transcutaneous electrical nerve stimulation for treatment of hyperalgesia and pain. Curr Rheumatol Rep. 2008;10(6):492-499.

12. Norman AT, Judkins KC. Pain in the patient with burns. Critical Care Pain. 2004;4(2):57-61.

13. Sabino GS, Santos CM, Francischi JN, de Resende MA. Release of endogenous opioids following transcutaneous electric nerve stimulation in an experimental model of acute inflammatory pain. J Pain. 2008;9:157-163.

14. Trupkovic T, Kinn M, Kleinschmidt S. Analgesia and sedation in the intensive care of burn patients: results of a European survey. J Intensive Care Med. 2011;26(6):397-407.

15. Moran JL, Bristow P, Solomon PJ, George C, Hart GK; Australian and New Zealand Intensive Care Society Database Management Committee (ADMC). Mortality and length-of-stay outcomes, 1993-2003, in the binational Australian and New Zealand intensive care adult patient database. Crit Care Med. 2008;36(1):46-61. 


\section{Publish your work in this journal}

Local and Regional Anesthesia is an international, peer-reviewed, open access journal publishing on the development, pharmacology, delivery and targeting and clinical use of local and regional anesthetics and analgesics. The journal welcomes submitted papers covering original research, basic science, clinical studies, reviews \& evaluations,

guidelines, expert opinion and commentary, case reports and extended reports. The manuscript management system is completely online and includes a very quick and fair peer-review system, which is all easy to use. Visit http://www.dovepress.com/testimonials.php to read real quotes from published authors.

Submit your manuscript here: http://www.dovepress.com/local-and-regional-anesthesia-journal 